\title{
Cytochrome b-245 Alpha Chain Gene Variants and Arterial Function in Indonesian Short Stature Children
}

\author{
Nani Maharania, b (D), Anindita Soetadji ${ }^{\mathrm{c}}$, Agustini Utari ${ }^{\mathrm{a}, \mathrm{c}}{ }^{\mathbb{B}}$, Izumi Naka ${ }^{\mathrm{d}}$, \\ Jun Ohashi ${ }^{\mathrm{d}}$, Maria Mexitalia ${ }^{\mathrm{c}, \mathrm{e}}\left[{ }^{\circ}\right.$
}

\begin{abstract}
Background: The association between short stature, undernutrition and the risk to cardiovascular disease has been clinically established. Genetic factor, particularly the variants in cytochrome b-245 alpha chain $(C Y B A)$ gene, which alter the formation of nicotinamide adenine dinucleotide phosphate (NADPH) oxidase level, might affect arterial function. This study aimed to observe the association between single nucleotide variants (SNVs) of the CYBA gene and the arterial function of short stature children to understand the reason why some people with short stature develop cardiovascular disease.
\end{abstract}

Methods: A total of 142 genomic deoxyribonucleic acid (DNA) samples have been collected from short stature children in Brebes, Central Java, Indonesia. Four common single-nucleotide polymorphisms (SNPs): C242T (rs4673), A640G (rs1049255), -930A >G (rs9932581) and *49A $>\mathrm{G}$ (rs7195830) in the CYBA gene were examined using TaqMan allelic discrimination assay. The arterial function was measured using transthoracic echocardiography and described as aortic stiffness and distensibility index. Statistical analysis was done to find a significant difference in arterial function between genotypes of each SNV.

Results: A P-value of $<0.05$ was considered significant. In rs9932581 $(-930 \mathrm{~A}>\mathrm{G})$ of $C Y B A$ gene, the subjects with $\mathrm{GG}$ genotype were found to have significantly lower arterial stiffness and higher distensibility compared to AA and AG genotypes. No significant difference was found in the other SNVs.

Conclusion: The GG genotype in rs9932581 of the CYBA gene

Manuscript submitted July 31, 2021, accepted October 5, 2021

Published online November 11, 2021

${ }^{a}$ Center for Biomedical Research, Faculty of Medicine, Universitas Diponegoro, Semarang, Indonesia

bDepartment of Pharmacology and Therapy, Faculty of Medicine, Universitas Diponegoro, Semarang, Indonesia

'Department of Pediatrics, Faculty of Medicine, Universitas Diponegoro/Dr Kariadi Hospital, Semarang, Indonesia

dDepartment of Biological Sciences, Graduate School of Science, The University of Tokyo, Tokyo, Japan

${ }^{e}$ Corresponding Author: Maria Mexitalia, Department of Pediatrics, Faculty of Medicine, Universitas Diponegoro/Dr Kariadi Hospital, Jalan Dr. Soetomo No. 16, Semarang 50244, Indonesia. Email: dr.mexitalia@gmail.com

doi: https://doi.org/10.14740/cr1314 might have a protective effect on cardiovascular disease in short stature children.

Keywords: Aortic stiffness; NADPH oxidase; Short stature; $C Y B A$ gene

\section{Introduction}

The prevalence of short stature in Indonesian children is high. It becomes an important issue because children with short stature pose an increased risk of obesity, metabolic diseases, as well as coronary heart disease in adulthood [1-3]. Early changes in cardiovascular parameters, such as lower arterial elasticity, stroke volume, and higher peripheral resistance have occurred in adolescents with short stature. These early changes, particularly the lower atrial elasticity, might change the vascular function of those children, causing the development of hypertension later in their adulthood life [4].

Short stature is known to be associated with lower insulinlike growth factor-1 (IGF-1) [5]. IGF-1 does not only play a role in linear growth, but also in maintaining vascular function by triggering the formation of nitric oxide (NO) via phosphatidylinositol 3 kinase/Akt pathway. Endothelial cells released NO that diffused into vascular smooth muscle cells (VSMCs) leading to dilation of the blood vessels [6-8]. A study by Aly et al showed that nutritionally stunted children had a higher level of oxidative stress and lower antioxidant defense systems than healthy controls [9]. The balance between oxidant and antioxidant in the body determined the health status of our cardiovascular system.

Cytochrome b-245 alpha chain (CYBA) gene is located on chromosome 16q24. It encodes p22phox, one of the electron transfer elements of nicotinamide adenine dinucleotide phosphate (NADPH) oxidase. The expression of p22phox in VSMCs is a critical component for the formation of reactive oxygen species [10]. Some variants of the CYBA gene have been reported, such as C242T, A640G, $-930 \mathrm{~A}>\mathrm{G}, * 49 \mathrm{~A}>\mathrm{G}$, $-675 \mathrm{~A} / \mathrm{T}$ and $\mathrm{C} 549 \mathrm{~T}$. Among those, four single nucleotide variants (SNVs), C242T (rs4673), A640G (rs1049255), -930A > G (rs9932581) and *49A>G (rs7195830), have been most extensively investigated in the association studies of coronary artery disease (CAD) [11].

There are conflicting results on the role of these variants in 
CAD. However, a meta-analysis study by Xu et al showed that C242T has a protective effect on CAD in Asian populations. It is also found that $\mathrm{A} 640 \mathrm{G}$ was associated with lower risk of CAD. The C242T variant caused a decrease in oxidative function, and lower reactive oxygen species (ROS) production. The NADPH oxidase activity in human blood vessels is thus reduced [11]. The A640G is located in the 3'untranslated region (UTR) of $C Y B A$ gene and interacts with the neighboring regions. It plays a role in the modification of mRNA's stability and the translational activity of $C Y B A$ [12]. The $-930 \mathrm{~A}>\mathrm{G}$ is located in the promoter. This variant caused higher transcriptional activity, mRNA and protein expression of the $C Y B A$ gene, as well as NADPH oxidase activity, in hypertensive patients $[13,14]$. The $* 49 \mathrm{~A}>\mathrm{G}$ variant may modify the risk of $\mathrm{CAD}$ in patients with premature CAD [15].

Our preliminary study at the beginning of 2014 which enrolled 50 school children aged 9 - 12 years in Brebes Central Java showed that $28 \%(14 / 50)$ of children were short stature. The result showed that the IGF-1 level in the preliminary study was only weakly correlated with arterial stiffness/body surface area index [16].

Based on the results of those previous studies, we examined the association of four common SNVs of the CYBA gene with the arterial function of short stature children to see whether genetics play a part in the cardiovascular function of the children.

\section{Materials and Methods}

This was an observational study to analyze the association between the $C Y B A$ variants and the arterial elasticity in children with short stature. This study has received ethical clearance from the Commission on Health Research Ethics Faculty of Medicine Diponegoro University and Dr Kariadi Hospital, with the number: 02/EC/FK-RSDK/IV/2018. Informed parental consents had been obtained prior to samples collection.

\section{Subjects}

Subjects were short stature children (height for age score $\leq$ -2 standard deviation (SD)) aged 9 - 12 years old in grades 3-5 elementary in Brebes, Central Java, Indonesia. Subjects with obesity and/or diabetes mellitus, and congenital diseases known to cause short stature and/or affect the aortic elasticity such as Turner syndrome, Down syndrome, Noonan syndrome, Marfan syndrome, William's syndrome, and congenital heart disease were excluded. A total of 142 samples were collected for their deoxyribonucleic acid (DNA). In all of the subjects, the data on age, sex, and body mass index (BMI) were taken.

\section{Determination of aortic stiffness and distensibility}

Arterial elasticity properties were measured from the arterial stiffness and distensibility. All subjects underwent transthoracic echocardiography, performed by pediatric cardiology, using a Logic E portable (General Electric) echocardiography device. Subjects with cardiac structural and functional abnormality were excluded after a thorough examination to rule those out.

M-mode measurement in parasternal long axis view was used to define the ascending aortic distensibility and stiffness. Measurement took place at $30 \mathrm{~mm}$ distal to aortic valve, with the subjects lying in supine position during examination. The data were collected three times for each subject, and then averaged.

The formulas for calculating distensibility and wall stiffness index are as follows: Distensibility $=(\mathrm{As}-\mathrm{Ad}) /(\mathrm{Ad} \times(\mathrm{Ps}$ - Pd $) \times 1,333) \times 10^{7}\left(10^{-3} \mathrm{kPa}^{-1}\right)$, and Stiffness index $=(\ln (\mathrm{Ps} /$ $\mathrm{Pd})] /((\mathrm{Ds}-\mathrm{Dd}) / \mathrm{Dd})$ (dimensionless), where As is systolic area, Ad is end-diastolic area, Ps is SBP, and Pd is DBP (both in $\mathrm{mm}$ $\mathrm{Hg})$. Area A was determined as $\left(\mathrm{A}=(\mathrm{D} / 2)^{2} \times \mathrm{Pi}\right)[17]$.

\section{Extraction of genomic DNA}

The extraction of genomic DNA was done in Center for Biomedical Research Laboratory of Faculty of Medicine Diponegoro University Indonesia, using salting-out method. EDTA blood was put in the falcon tube, and $5-10 \mathrm{~mL}$ of lysis buffer $\mathrm{NH}_{4} \mathrm{Cl}$ was added. After hemolysis, the tubes were centrifuged for $5 \mathrm{~min}$ at 3,000 - 3,500 rpm at room temperature. The supernatant was then discarded and $\mathrm{NH}_{4} \mathrm{Cl}$ lysis buffer was added, and once again the supernatant was removed to obtain a white pellet. Two milliliters of TE buffer Strong/TE lysis was added into white pellets, and $30-50 \mu \mathrm{L}$ proteinase $\mathrm{K}$ was added. A hundred microliters of $10 \%$ sodium dodecyl sulfate (SDS) was added, mixed, and then put into the $50{ }^{\circ} \mathrm{C}_{2} \mathrm{O}$ bath overnight. For the extraction and precipitation, $6 \mathrm{M} \mathrm{NaCl}$ was added. Tubes were centrifuged for $10 \mathrm{~min}$ at $10 \mathrm{rpm}$, the supernatant containing DNA was taken and transferred to a new tube, and $2 \times$ volume of $100 \%$ ethanol was added. The DNA was taken and washed with 70\% ethanol, and moved into a $1.5 \mathrm{~mL}$ Eppendorf tube. Normal TE buffer was added as much as $300-500$ $\mu \mathrm{L}$ to dissolve the DNA at least overnight at room temperature.

\section{TaqMan allelic discrimination assay}

The TaqMan allelic discrimination assay was done at the Department of Biological Sciences, Graduated School of Sciences, The University of Tokyo. It was used to genotype four SNPs on the CYBA gene: C242T (rs4673), A640G (rs1049255), $-930 A>G(r s 9932581)$ and $* 49 A>G(r s 7195830)$. The polymerase chain reaction (PCR) was done in a total reaction volume of $10 \mu \mathrm{L}$, which consisted of $3.875 \mu \mathrm{L}$ MilliQ $\mathrm{H}_{2} \mathrm{O}, 5 \mu \mathrm{L}$ TaqMan universal PCR master mix, $0.125 \mu \mathrm{L}$ TaqMan probe and $1 \mu \mathrm{L}$ DNA with the concentration of $10 \mathrm{ng} / \mu \mathrm{L}$. A commercially available TaqMan probe (Applied Biosystem Inc.) for the rs4673 (C242T), rs9932581(-930A $>\mathrm{G})$, and rs7195830 $(* 49 \mathrm{~A}>\mathrm{G})$ was used in addition to a custom-made rs 1049255 probe for A640G variant. PCR program was run for initial denaturation for $10 \mathrm{~min}$ at $95^{\circ} \mathrm{C}$, followed by $15 \mathrm{~s}$ of denaturation at $92{ }^{\circ} \mathrm{C}$, and $60 \mathrm{~s}$ of annealing and extension at $60{ }^{\circ} \mathrm{C}$, 
Table 1. Samples Characteristics

\begin{tabular}{lll}
\hline Variables & Frequency/mean & SD \\
\hline Sex $\quad$ & & \\
$\quad$ Male & $80(56.3 \%)$ & \\
$\quad$ Female & $62(43.7 \%)$ & 0.91 \\
Age (years) & 10.09 & 0.59 \\
Height for age (z score) & -2.38 & 1.03 \\
BMI (z score) & -1.38 & 0.15 \\
Aortic ascending diameter during systole & 1.75 & 0.17 \\
Aortic ascending diameter during diastole & 1.50 & 1.78 \\
Aortic stiffness index & 1.78 & 53.86 \\
Aortic distensibility index & 76.58 & \\
\hline
\end{tabular}

BMI: body mass index; SD: standard deviation.

repeated for 40 cycles. After PCR, allele-specific fluorescence was measured using ABI 7300 (Applied Biosystem Inc.). Genotype frequencies were tested in accordance with Hardy-Weinberg equilibrium (HWE). The data were analyzed in Haploview using the standard transmission disequilibrium test (TDT). P-values below 0.05 were considered statistically significant.

\section{Statistical analysis}

The coding and tabulation of data into the computer, the processing, analysis, and presentation were done using SPSS software version 20.0 (Polar Engineering and Consulting, USA). All of the variances were tested for deviation from the HWE using a Chi-square analysis. To assess the correlation between genotype and phenotype (the arterial elasticity), bivariate and multivariate analyses were used. Differences with a P-value of $<0.05$ were considered statistically significant.

\section{Results}

\section{Samples characteristics}

In total, 142 DNA samples were collected from the subjects aged 8 - 11 years old. The characteristics of the samples are presented in Table 1. Most of the children included in this study were male, with the mean age of 10.09 years old, and the body mass index (BMI) above -2 . Aortic stiffness and distensibility index were 1.78 and 76.58 , respectively, which are in the normal range.

\section{Allele frequency and HWE}

The allele frequency for each SNV is reported in Table 2. None of four SNVs were significantly deviated from the HWE. The frequencies of variants allele were in concordance with the literature and databases, except for rs7195830 $(* 49 A>G)$, in which the $\mathrm{G}$ allele carriers were more than the A carriers.

\section{Association between genotypes and aortic stiffness index}

In rs4673, rs7195830 and rs1049255, there was no significant difference in aortic stiffness index between genotypes. In rs9932581 (-930A > G), GG homozygosity was associated with the lower aortic stiffness index (Table 3 ).

\section{Association between genotypes and aortic distensibility}

In line with the result in aortic stiffness index, the GG genotype in rs9932581 (-930A $>$ G) was significantly associated with higher aortic distensibility index (Table 4). Other SNVs showed no significant difference in aortic stiffness index.

\section{Discussion}

Children with short stature were found to have a higher risk of cardiovascular disease in their adulthood, either for congestive heart disease, myocardial infarct, or all cardiovascular disease mortality, compared to those who are taller [1]. This condition might be related to a higher risk of abdominal fat accumulation which is the predictor of metabolic alterations in stunted children [18]. In this research, the average BMI values of the children are between 1 and 2 standard deviation (SD) below the WHO standard; however, the abdominal fats were not measured. It is important to differentiate non-nutritional from nutritional short stature, as the vascular elasticity in nonnutritional short stature might be caused by other specific conditions, apart from NO and ROS imbalance. In this study, we did a screening for the presence of syndromes which can affect either the short stature or the aortic elasticity, namely Turner syndrome, Down syndrome, Noonan syndrome, Marfan syndrome, William's syndrome, and congenital heart diseases. Measuring the serum IGF-1 level has been accepted as a screening tool for nutritional short stature, and it could be a confounding factor for this study [19]. But with the prescreening for non-nutritional short stature, although it could not cover the whole needs for the differentiation, at least we 
Table 2. Allele Frequencies

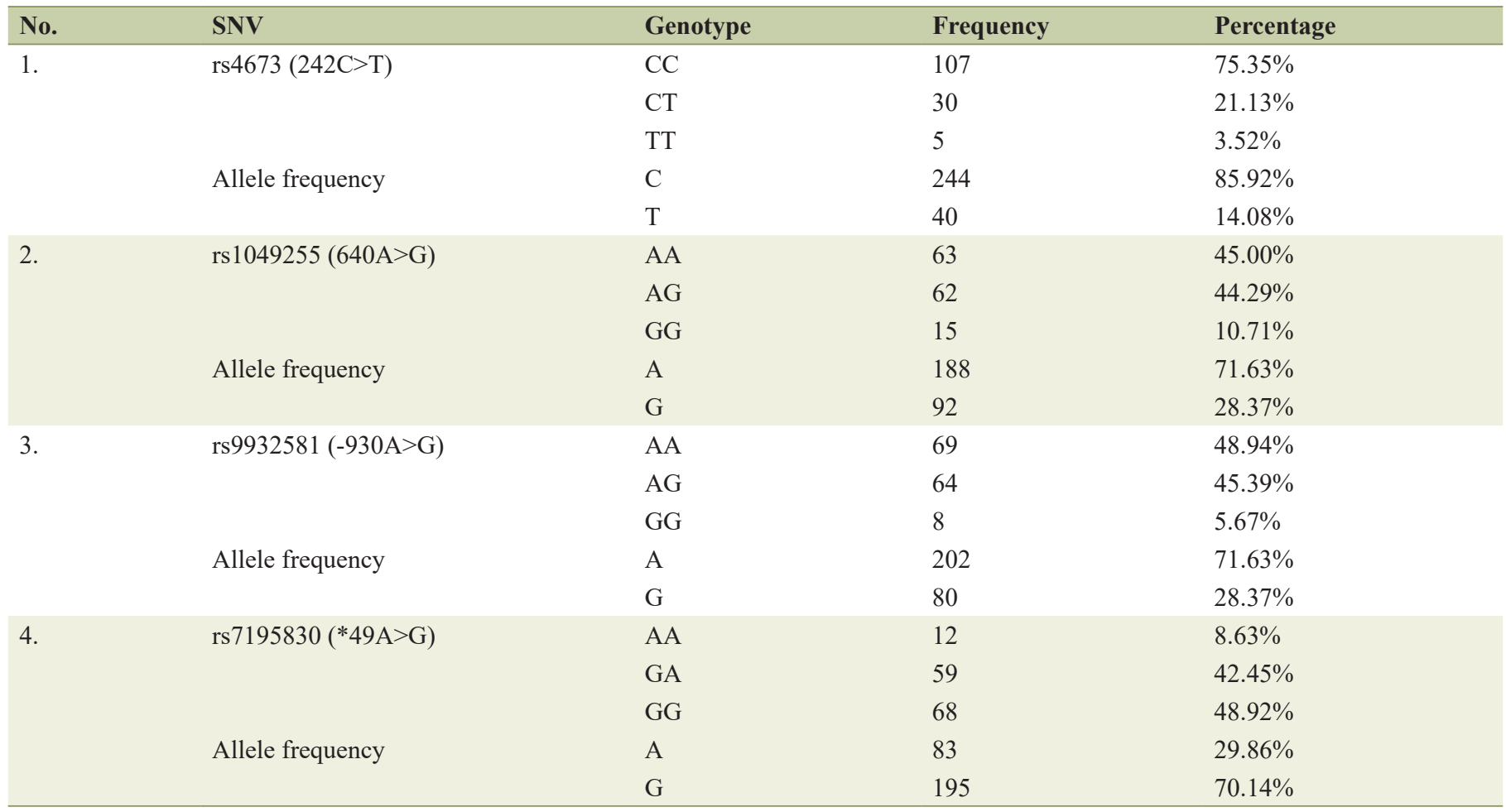

SNV: single nucleotide variant.

Table 3. Association Between Genotypes and Aortic Stiffness Index

\begin{tabular}{|c|c|c|c|}
\hline SNV & Genotype & Mean of aortic stiffness index & $\mathbf{P}$ \\
\hline \multirow[t]{4}{*}{ rs4673 $(242 \mathrm{C}>\mathrm{T})$} & $\mathrm{CC}$ & $2.39 \pm 0.54$ & $0.623^{\mathrm{a}}$ \\
\hline & $\mathrm{CT}$ & $2.29 \pm 0.54$ & \\
\hline & $\mathrm{CC}+\mathrm{CT}$ & $2.37 \pm 0.54$ & $0.74^{\mathrm{c}}$ \\
\hline & $\mathrm{TT}$ & $2.45 \pm 1.09$ & \\
\hline \multirow{3}{*}{ rs1049255 (640A>G) } & GG & $2.25 \pm 0.76$ & \\
\hline & $\mathrm{AA}+\mathrm{AG}$ & $2.39 \pm 0.54$ & $0.372^{c}$ \\
\hline & GG & $2.25 \pm 0.76$ & \\
\hline \multirow[t]{2}{*}{ rs9932581 (-930A>G) } & $\mathrm{AA}$ & $2.35 \pm 0.48$ & $0.048^{a *}$ \\
\hline & GG & $1.93 \pm 0.70$ & \\
\hline \multirow[t]{5}{*}{ rs7195830 $(* 49 \mathrm{~A}>\mathrm{G})$} & $\mathrm{AA}$ & $2.32 \pm 0.25$ & $0.805^{\mathrm{b}}$ \\
\hline & $\mathrm{AG}$ & $2.33 \pm 0.46$ & \\
\hline & GG & $2.43 \pm 0.68$ & \\
\hline & $\mathrm{AA}+\mathrm{AG}$ & $2.33 \pm 0.43$ & $0.335^{\mathrm{c}}$ \\
\hline & GG & $2.43 \pm 0.68$ & \\
\hline
\end{tabular}

${ }^{*} \mathrm{P}<0.05 .{ }^{a} \mathrm{ANOVA} .{ }^{\mathrm{b}} \mathrm{Kruskal}-$ Wallis. ${ }^{\mathrm{C}}$-test. ANOVA: analysis of variance; SNV: single nucleotide variant. 
Table 4. Association Between Genotypes and Aortic Distensibility

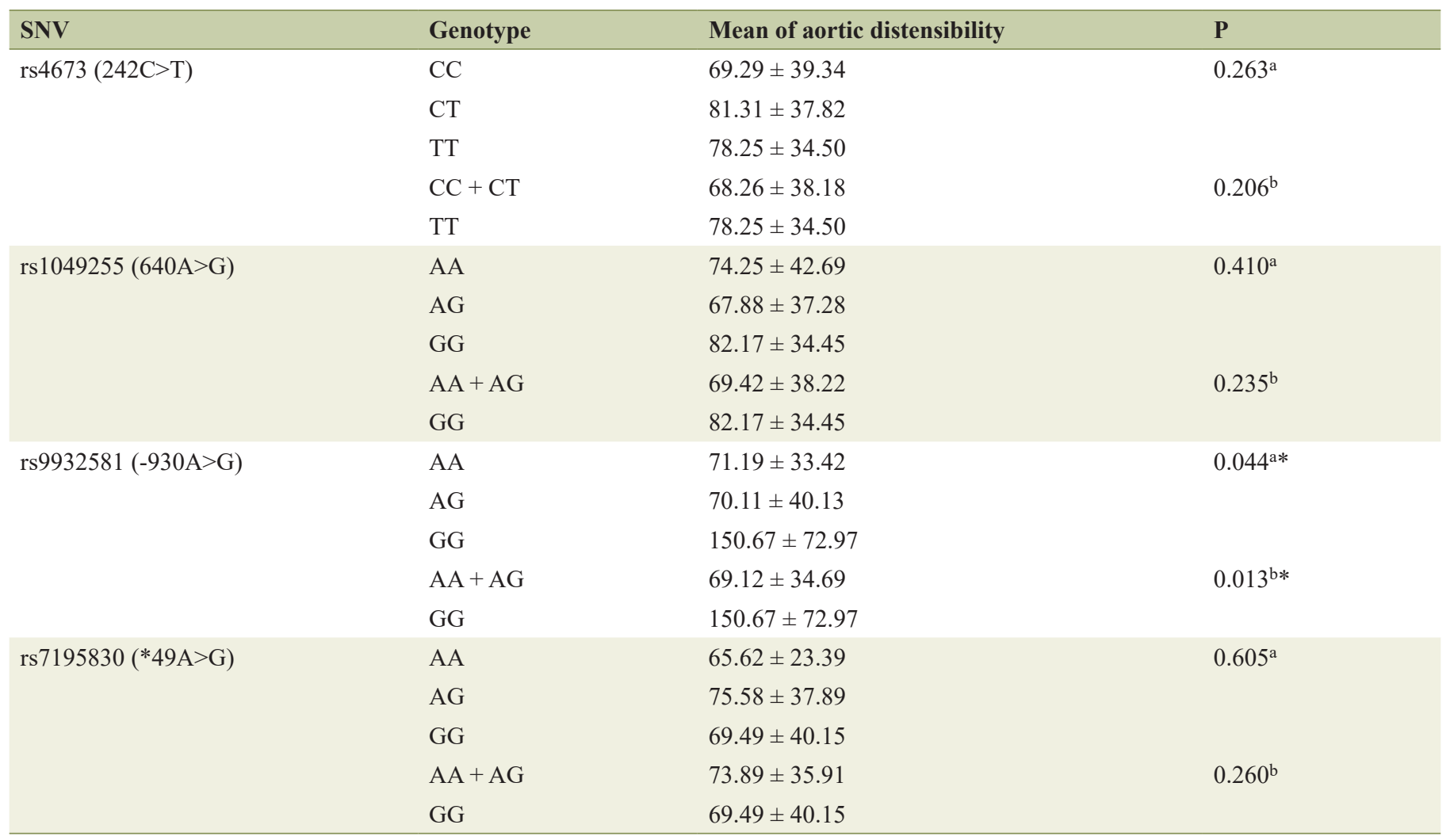

${ }^{*} \mathrm{P}<0.05$. aANOVA. ${ }^{b} t$-test. ANOVA: analysis of variance; SNV: single nucleotide variant.

can be more certain that it might be nutritional. Moreover, the p22phox encoded by $C Y B A$ gene plays a direct role in the vascular elasticity through the formation of ROS [10]. The effect of the confounding factor can be even less.

The presence of $-930 \mathrm{~A}>\mathrm{G}$ variant in the promoter of $C Y B A$ gene leads to higher transcription levels of p22phox compared to the wild type, and it might interact with the CCAAT/enhancer-binding protein $\partial(\mathrm{C} / \mathrm{EBP})[20]$. This leads to increased proliferation of VSMC, production of ROS, and endothelial dysfunction which may contribute to cerebrovascular disease [21]. The association between $-930 \mathrm{~A}>\mathrm{G}$ and hypertension has been reported; however, controversial results have been published with regard to this association of the GG genotype and hypertension $[22,23]$. Most of the publications contradict our finding, except a case-control study by Goliasch et al which suggested that the c.-930A $>$ G promoter variants might act as a protective factor for the development of myocardial infarction in young individuals ( $\leq 40$ years) [24]. The different characteristic of the subjects included in the study might be the reason for our different finding. In this study, we included only those with height $\mathrm{z}$-score of -2 or less and see whether the presence of variant affected arterial function.

There was no significant association of the other $C Y B A$ gene variants with the arterial function. This seems different from other findings that reported the association between C242T variant and a higher risk of CAD in the young $(<45$ years) [25], or the relationship between the variant with the progressivity of asymptomatic atherosclerosis in type 2 diabetics and insulin resistance in non-diabetics [26]. However, it is important to notice that the association between C242T with an increased risk of CAD was known to be related to a reduced basal and NADPH-stimulated ROS production [27]. This phenomenon suggested that reduction in NADPH activity, with the consequence of a decrease in ROS production, leads to the progression of atherosclerosis in young individuals. So, in this case, a variant that up-regulates the NADPH activity and increases ROS production might function as a protective factor, especially in children or young adults [24]. Some in-vitro studies support this idea that preconditioning the endothelial cells with ROS reduced the inflammatory response [28, 29].

Our study has some limitations to be considered. First of all, this study was performed only in short stature children. Thus, the same association may not be found in normal stature children. Second, the parameter of arterial functions might be measured too early to show a disturbance in the cardiovascular system. A cohort study on the same population would be needed to show whether or not the examination on $C Y B A$ gene variant brings advantage in predicting cardiovascular morbidity in those children. Thirdly, we did not do IGF-1 level and hormonal examination, as well as parental height measurement, which could become confounding factors. Finally, compared to other populations, the $\mathrm{G}$ allele frequency in $-930 \mathrm{~A}>\mathrm{G}$ in our study was lower $(0.28)$ than in Chinese $(0.36)$ or Bra- 
zilian $(0.37)$ [21, 30]. The difference in ethnicity might influence the result, thus a larger study comprising various ethnics is suggested.

\section{Conclusion}

The GG genotype in rs9932581 of the CYBA gene might have a protective effect on cardiovascular disease in short stature children.

\section{Acknowledgments}

The authors would like to thank the subjects for their participation in this study.

\section{Financial Disclosure}

This study was funded by the grant from Lembaga Penelitian dan Pengabdian Masyarakat (LPPM) of Universitas Diponegoro, Indonesia, with the grant number: $385-74 /$ UN7.P4.3/ $\mathrm{PP} / 2018$.

\section{Conflict of Interest}

The authors declare no conflict of interest.

\section{Informed Consent}

Informed consent has been obtained.

\section{Author Contributions}

MM, AS, AU, and NM designed the study; AS, MM, and AU collected the data on BMI; NM, MM, and IN collected the data on genotypes; AS collected the data on arterial function; NM and JO analyzed the data; NM and AS wrote the manuscript. All authors read and approved the final manuscript.

\section{Data Availability}

The authors declare that data supporting the findings of this study are available within the article.

\section{Abbreviations}

CYBA: cytochrome b-245 alpha chain; NADPH: nicotinamide adenine dinucleotide phosphate; DNA: deoxyribonucleic acid; SNV: single nucleotide variant; IGF-1: insulin-like growth factor-1; NO: nitric oxide; VSMC: vascular smooth muscle cell; CAD: coronary artery disease; UTR: untranslated region; BMI: body mass index; SBP: systolic blood pressure; DBP: diastolic blood pressure; EDTA: ethylenediaminetetraacetic acid; $\mathrm{NH}_{4} \mathrm{Cl}$ : ammonium chloride acid; SDS: sodium dodecyl sulphate; TE: tris-EDTA; TDT: transmission disequilibrium test; HWE: Hardy Weinberg equilibrium; ROS: reactive oxygen species

\section{References}

1. Paajanen TA, Oksala NK, Kuukasjarvi P, Karhunen PJ. Short stature is associated with coronary heart disease: a systematic review of the literature and a meta-analysis. Eur Heart J. 2010;31(14):1802-1809.

2. Dewey KG, Begum K. Long-term consequences of stunting in early life. Matern Child Nutr. 2011;7(Suppl 3):518.

3. de Onis M, Blossner M, Borghi E. Prevalence and trends of stunting among pre-school children, 1990-2020. Public Health Nutr. 2012;15(1):142-148.

4. van Rooyen JM, Kruger HS, Huisman HW, Schutte AE, Malan NT, Schutte R. Early cardiovascular changes in 10- to 15-year-old stunted children: the Transition and Health during Urbanization in South Africa in Children study. Nutrition. 2005;21(7-8):808-814.

5. Prendergast AJ, Rukobo S, Chasekwa B, Mutasa K, Ntozini R, Mbuya MN, Jones A, et al. Stunting is characterized by chronic inflammation in Zimbabwean infants. PLoS One. 2014;9(2):e86928.

6. Conti E, Carrozza C, Capoluongo E, Volpe M, Crea F, Zuppi C, Andreotti F. Insulin-like growth factor-1 as a vascular protective factor. Circulation. 2004;110(15):22602265.

7. Empen K, Lorbeer R, Volzke H, Robinson DM, Friedrich N, Krebs A, Nauck M, et al. Association of serum IGF1 with endothelial function: results from the populationbased study of health in Pomerania. Eur J Endocrinol. 2010;163(4):617-623.

8. Ungvari Z, Csiszar A. The emerging role of IGF-1 deficiency in cardiovascular aging: recent advances. J Gerontol A Biol Sci Med Sci. 2012;67(6):599-610.

9. Aly GS, Shaalan AH, Mattar MK, Ahmed HH, Zaki ME, Abdallah HR. Oxidative stress status in nutritionally stunted children. Egyptian Pediatric Association Gazette. 2014;62(1):28-33.

10. Nasti S, Spallarossa P, Altieri P, Garibaldi S, Fabbi $\mathrm{P}$, Polito L, Bacino L, et al. C242T polymorphism in CYBA gene (p22phox) and risk of coronary artery disease in a population of Caucasian Italians. Dis Markers. 2006;22(3):167-173.

11. Xu Q, Yuan F, Shen X, Wen H, Li W, Cheng B, Wu J. Polymorphisms of C242T and A640G in CYBA gene and the risk of coronary artery disease: a meta-analysis. PLoS One. 2014;9(1):e84251.

12. Niemiec P, Nowak T, Balcerzyk A, Krauze J, Zak I. The CYBA gene A640G polymorphism influences predispositions to coronary artery disease through interactions with cigarette smoking and hypercholesterolemia. Bio- 
markers. 2011;16(5):405-412.

13. Niemiec P, Nowak T, Iwanicki T, Krauze J, GorczynskaKosiorz S, Grzeszczak W, Ochalska-Tyka A, et al. The $-930 \mathrm{~A}>\mathrm{G}$ polymorphism of the CYBA gene is associated with premature coronary artery disease. A case-control study and gene-risk factors interactions. Mol Biol Rep. 2014;41(5):3287-3294.

14. Tupurani MA, Padala C, Puranam K, Galimudi RK, Kupsal K, Shyamala N, Gantala S, et al. Association of CYBA gene $(-930 \mathrm{~A} / \mathrm{G}$ and $242 \mathrm{C} / \mathrm{T})$ polymorphisms with oxidative stress in breast cancer: a case-control study. PeerJ. 2018;6:e5509.

15. Nowak T, Niemiec P, Gorczynska-Kosiorz S, Balcerzyk A, Iwanicki T, Krauze J, Grzeszczak W, et al. The CYBA gene ()49A $>$ G polymorphism (rs7195830) is associated with hypertension in patients with coronary artery disease. Biomed Res Int. 2016;2016:1539671.

16. Soetadji A, Suhartono, Kartini A, Budiyono, Hardaningsih G, Utari A. Aortic elasticity profile of children living in area of chronic organophosphate exposure: a preliminary study. Procedia Environmental Sciences. 2015;23:6.

17. Hauser M, Kuhn A, Petzuch K, Wolf P, Vogt M. Elastic properties of the ascending aorta in healthy children and adolescents. Age-related reference values for aortic wall stiffness and distensibility obtained on M-mode echocardiography. Circ J. 2013;77(12):3007-3014.

18. Clemente AP, Santos CD, Silva AA, Martins VJ, Marchesano AC, Fernandes MB, Albuquerque MP, et al. Mild stunting is associated with higher blood pressure in overweight adolescents. Arq Bras Cardiol. 2012;98(1):6-12.

19. Hawkes CP, Grimberg A. Insulin-like growth factor-I is a marker for the nutritional state. Pediatr Endocrinol Rev. 2015;13(2):499-511.

20. Moreno MU, San Jose G, Orbe J, Paramo JA, Beloqui O, Diez J, Zalba G. Preliminary characterisation of the promoter of the human p22(phox) gene: identification of a new polymorphism associated with hypertension. FEBS Lett. 2003;542(1-3):27-31.

21. Zhou Y, Zhao YC. Association between the nicotinamide adenine dinucleotide phosphate oxidase p22phox gene
-A930G polymorphism and intracerebral hemorrhage. Mol Med Rep. 2015;11(5):3511-3516.

22. Moreno MU, Zalba G. CYBA gene variants as biomarkers for coronary artery disease. Drug News Perspect. 2010;23(5):316-324.

23. Qin YW, Peng J, Liang BY, Su L, Chen Q, Xie JJ, Gu L. The A930G polymorphism ofP22phox (CYBA) gene but not $\mathrm{C} 242 \mathrm{~T}$ variation is associated with hypertension: a meta-analysis. PLoS One. 2013;8(12):e82465.

24. Goliasch G, Wiesbauer F, Grafl A, Ponweiser E, Blessberger H, Tentzeris I, Wojta J, et al. The effect of p22PHOX (CYBA) polymorphisms on premature coronary artery disease $(</=40$ years of age $)$. Thromb Haemost. 2011;105(3):529-534.

25. Cai H, Duarte N, Wilcken DE, Wang XL. NADH/NADPH oxidase $\mathrm{p} 22$ phox C242T polymorphism and coronary artery disease in the Australian population. Eur J Clin Invest. 1999;29(9):744-748.

26. Hayaishi-Okano R, Yamasaki Y, Kajimoto Y, Sakamoto K, Ohtoshi K, Katakami N, Kawamori D, et al. Association of $\mathrm{NAD}(\mathrm{P}) \mathrm{H}$ oxidase $\mathrm{p} 22$ phox gene variation with advanced carotid atherosclerosis in Japanese type 2 diabetes. Diabetes Care. 2003;26(2):458-463.

27. Guzik TJ, West NE, Black E, McDonald D, Ratnatunga C, Pillai R, Channon KM. Functional effect of the C242T polymorphism in the $\mathrm{NAD}(\mathrm{P}) \mathrm{H}$ oxidase p22phox gene on vascular superoxide production in atherosclerosis. Circulation. 2000;102(15):1744-1747.

28. Zahler S, Kupatt C, Becker BF. Endothelial preconditioning by transient oxidative stress reduces inflammatory responses of cultured endothelial cells to TNF-alpha. FASEB J. 2000;14(3):555-564.

29. Becker LB. New concepts in reactive oxygen species and cardiovascular reperfusion physiology. Cardiovasc Res. 2004;61(3):461-470.

30. Sales ML, Ferreira MC, Leme CA, Jr., Velloso LA, Gallani MC, Colombo RC, Franchini KG, et al. Non-effect of p22-phox -930A/G polymorphism on end-organ damage in Brazilian hypertensive patients. J Hum Hypertens. 2007;21(6):504-506. 